\title{
Revisiting the Arctic City: 50-years of Pneumatic Progress and Perspective - STRUCTURAL MEMBRANES 2021
}

\author{
Rob Whitehead \\ Iowa State University, Department of Architecture \\ Ames, Iowa, United States \\ Email: rwhitehd@iastate.edu
}

\begin{abstract}
This paper will use a construction-history methodology to examine the architectural and structural implications of a renowned 1971 proposal, The Arctic City: A $2 \mathrm{~km}$ wide, $240 \mathrm{~m}$ tall pneumatic enclosure intended to house 40,000 people for a mining operation on an estuary in the Arctic Circle

[1]. The proposal, created by Frei Otto, Kenzo Tange, and Arup embodied a convergence of ideologies that elevated ingenuity in structural design to the forefront of broader discussion of human occupation in extreme ecological conditions. The designers believed that innovations in design science could help envision a resilient and quasi-utopian future for how, and where, humans might eventually live - a proposal that is particular relevant today, 50 years later.
\end{abstract}

The paper will contextualize the designer's work and broader pneumatic design efforts in this era as a way of providing insight into their ideologies and the technical limits they encountered. Otto's earliest design and research efforts, focused nearly exclusively on how pneumatics could assist humanitarian efforts by providing lightweight and adaptable shelter and infrastructure, even in extreme conditions [2]. Tange specialized in futuristic megastructure / infrastructural system designs, and Arup's Structures 3 division was the leading specialist in innovative engineering.

Technically the proposal was innovative with merits and limitations that remain relevant. By 1971, pneumatics had long been used in feasibility proposals for massive free-spanning structures, as the engineering calculations were easier to confirm than other lightweight structures [3]. Because of the climate conditions of wind, snow, and weather variations, they proposed a grid of high-strength polyester fiber cables, and a unique (pre-ETFE) double-layer pillowed membrane that would have ideally allowed the enclosure to act more as a skin rather than a true dome - other technical aspects were less successful in retrospect. Overall, they developed details for many living and working conditions in (and out) of the dome which are illustrative of extreme climate concerns we face today.

Eventually Otto criticized the proposal's scale and its disregard /technical defiance of the inherent climate conditions of the Arctic. But the uniqueness of this proposal, and the relevance of reexamining it, lies in the intersectional qualities of structural membrane design (design methods, environmental aspects, new membrane materials, etc.) as well as the manner in which it elevates structural ingenuity to humanitarian efforts to find resiliency, and challenges, in living with changing climate conditions [4].

\section{REFERENCES}

[1] W. Nerdinger, Ed., Frei Otto Complete Works, Lightweight Construction Natural Design, Birkhäuser, (2005).

[2] F. Otto, Tensile Structures, Vol. 1, Pneumatic Structures, MIT Press, (1967).

[3] P. Rice, "Lightweight Structures: Introduction," The Arup Journal, Vol. 15, No. 3, (1980).

[3] Matthew Jull, "Toward a Northern Architecture: The Microrayon as Arctic Urban Prototype," Journal of Architectural Education, 70:2,214-222, (2016). 